\title{
AN APPROACH TO DICOM EXTENSION FOR MEDICAL IMAGE STRAMING
}

\author{
DRAGAN, D. \& IVETIC, D.
}

Abstract: This paper represents an introduction to our work aiming at developing medical image streaming over DICOM networks. Medical image streaming represents a mechanism for efficient transmission of medical images to mobile devices. DICOM standard as de facto standard for medical image communication does not support image streaming. Therefore, to achieve medical image streaming it is necessary to extend DICOM standard with the support for image streaming. We researched whether DICOM can be extended and how should it be extended to support image streaming. Two transparent extensions of the standard DICOM message have been proposed: by a set of parameters or by a parameter string. Prototype applications have been developed to test these DICOM extensions. We favor the solution of parameter string based on JPIP syntax because it combines powerful JPEG2000 compression and JPEG2000 streaming over DICOM networks. The proposed extensions represent a solid ground for employing medical image streaming over DICOM networks.

Key words: PACS, DICOM, medical imaging, image streaming, JPEG2000
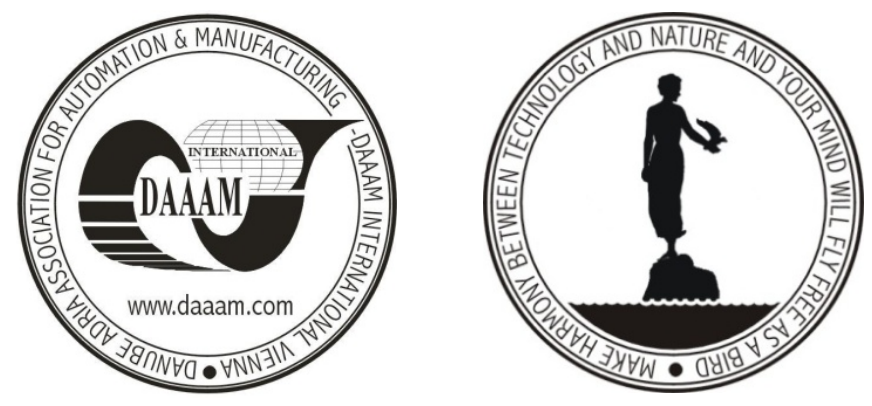

Authors' data: Teaching and research assistant ( $\mathrm{PhD}$ candidate) Dragan, $\mathrm{D}[\mathrm{inu}]$; Assoc. Prof. Dr. Sc. Ivetic, D[ragan], University of Novi Sad, Faculty of Technical Science, Department for Computing and Automatics, Trg D. Obradovica 6, 21000, Novi Sad, Republic of Serbia, dinud@uns.ac.rs, ivetic@uns.ac.rs

This Publication has to be referred as: Dragan, D[inu] \& Ivetic, D[ragan] (2009). An Approach to DICOM Extension for Medical Image Streaming, Chapter 04 in DAAAM International Scientific Book 2009, pp. 025-034, B. Katalinic (Ed.), Published by DAAAM International, ISBN 978-3-901509-69-8, ISSN 1726-9687, Vienna, Austria

DOI: $10.2507 /$ daaam.scibook.2009.04 